\title{
Práticas Criativas do Professor 2.0: atendendo às demandas da ciberinfância
}

\author{
Prof $^{\text {a }}$. Dra. Patricia Alejandra Behar ${ }^{1}$ \\ Prof ${ }^{\mathrm{a}}$. Dra. Leni Vieira Dornelles ${ }^{2}$ \\ Prof $^{\text {a }}$. Dra. Darli Collares ${ }^{3}$ \\ Msc. ${ }^{\text {anda }}$ Ana Paula Frozi de Castro e Souza ${ }^{1}$ \\ Ana Carolina Ribeiro Ribeiro ${ }^{1}$ \\ Ariane Nichele Cesar Longaray ${ }^{1}$ \\ Giovani Höber Ghiggi ${ }^{1}$
}

${ }^{1}$ Faculdade de Educação(FACED) / Núcleo de Tecnologia Digital Aplicada a Educação (NUTED) / Universidade Federal do Rio Grande do Sul (UFRGS) Porto Alegre - RS - Brasil

${ }^{2}$ Faculdade de Educação(FACED) / Grupo de Estudos em Educação Infantil (GEIN) / Universidade Federal do Rio Grande do Sul (UFRGS)

Porto Alegre - RS - Brasil

${ }^{3}$ Faculdade de Educação(FACED) Núcleo de Estudos sobre a Coordenação das Ações e o Ensinar e Aprender (NECAEA) / Universidade Federal do Rio Grande do Sul (UFRGS)

Porto Alegre - RS - Brasil

patricia.behar@ufrgs.br, ledornel@redemeta.com.br,d.collares@terra.com.br, nanafrozi@yahoo.com.br, carol_ribeiro2@hotmail.com, arianencl@yahoo.com.br, giovanihg@gmail.com

\section{RESUMO}

O presente artigo tem como objetivo apresentar os objetos de aprendizagem relacionados ao projeto de pesquisa "Professor 2.0: Buscando Práticas Criativas na Web”, desenvolvido pelo Núcleo de Tecnologia Digital Aplicada a Educação da Universidade Federal do Rio Grande do Sul. O referido projeto trata fundamentalmente da ciberinfância e suas ações criativas na Web 2.0 e tem por objetivo: 1) abordar o conceito de criatividade; 2) reorganizar modos de exercer a prática pedagógica a partir das ações criativas das crianças no meio digital. Essas pesquisas geraram dois objetos de aprendizagem que estão sendo validados através de um Curso de Extensão para Educadores.

Palavras-chave: Criatividade, Ciberinfância, Formação de Professores, Objetos de Aprendizagem

Teacher 2.0 creative practices: meeting new cyber-chilhood demands

\section{ABSTRACT}


This paper aims to present learning objects related to research project "Teacher 2.0: Searching the Web Creative Practice," developed by the Center for Digital Technology Applied to Education, Federal University of Rio Grande do Sul. This project deals fundamentally about the cyber-childhood and their creative actions on Web 2.0. Its goals are: 1) the concept of creativity; 2) remodel pedagogical practices ways starting from the creative actions of children in digital media. These surveys generated two learning objects that are being validated through an extension course for educators.

Keywords:: Creativity, Cyber-childhood, Teacher Trainning, Learning Objects

\section{INTRODUÇÃO}

Este estudo ${ }^{1}$ faz emergir duas temáticas que vêm sendo constantemente debatidas no contexto educacional atual, por um lado pensa a criatividade, por outro como os professores da Educação Infantil e dos anos iniciais do Ensino Fundamental podem inserir-se na cultura da sociedade em rede e operar com as ferramentas da Web 2.0, largamente utilizadas pelos alunos. Observa-se que as crianças contemporâneas fazem parte de uma geração que nasceu em contato com as tecnologias e descobriu o mundo por meio de diferentes mídias, através de ferramentas como computadores, iPhones, iPods, Internet sem fio (wirelless e 3G), entre tantos outros. Contudo, essas tecnologias estão cada vez mais presentes na sala de aula, remetendo professores e alunos a uma nova relação com o saber e com a aprendizagem. Assim, esta pesquisa busca fornecer subsídios a professores e gestores da educação, para que os mesmos possam utilizar-se desses recursos na sala de aula, colaborando para uma educação que parta do ponto de vista do aluno sobre aprendizagem e conhecimento utilizando ferramentas do computador e disponíveis na web.

Nessa perspectiva, propõe-se a criação de dois objetos de aprendizagem, através dos quais se busca o debate sobre as novas concepções de infância e como os professores estão lidando com as mesmas. Com essas novas infâncias, é essencial que os professores estejam desenvolvendo práticas pedagógicas que impulsionem as demandas utilizadas pelos alunos, como, por exemplo, as ferramentas disponibilizadas na Internet. Entre os objetos criados para esse projeto evidencia-se: “Práticas Criativas na Web 2.0” - a partir do conceito de criatividade, são apresentadas e aproveitadas pedagogicamente, as ferramentas utilizadas pelas crianças, que possa promover sua criatividade; "Professor 2.0 da Ciberinfância” - propõe a inserção dos “professores analógicos” nos mundos virtuais que são habitados por essa infância cyber, provocando a utilização orientada nesses espaços.

As demandas da formação de professores levaram o grupo a desenvolver tais materiais, chamando atenção para a concepção e as características de cada objeto, bem como sua proposta de validação através do Curso de Extensão iniciado em maio de 2010.

1 Referente ao projeto de pesquisa "Professor 2.0: Buscando Práticas Criativas na Web" desenvolvido pelo Núcleo de Tecnologia Digital aplicada à Educação (NUTED), juntamente com o Grupo de Estudos em Educação Infantil (GEIN) e o Núcleo de Estudos sobre a Coordenação das Ações e o Ensinar e Aprender (NECAEA), na Universidade Federal do Rio Grande do Sul. 


\section{A CIBERINFÂNCIA, OS HOMO ZAPPIENS E OS NATIVOS DIGITAIS: QUEM SÃO ESSES ALUNOS?}

As crianças contemporâneas fazem parte de uma geração que nasceu em contato com diferentes tecnologias e descobriu o mundo por meio de diversas mídias. Algumas pesquisas têm problematizado esta infância e analisado suas relações com o meio que a cerca, como o caso dos nativos digitais caracterizados por Prensky (2001) em uma perspectiva psicológica; sobre a ciberinfância estudada por Dornelles (2005) na dimensão cultural e dos homo zappiens enfocados por Veen e Vrakking (2009) em suas relações com a escola. Todos esses autores buscam entender como estas crianças estão lidando com o fluxo constante de informações e suas implicações na aprendizagem Nessa perspectiva, é preciso compreender o que essa nova geração de alunos traz para as escolas e como os professores podem aliar-se as potencialidades das redes e dos softwares sociais.

De acordo com Dornelles (2005) vive-se atualmente uma crise da infância que, como as demais crises, resulta em novos modos de se ver e se tratar as práticas diárias com as crianças. A criança passa a ser compreendida como alguém que pode estabelecer e produzir uma rede de práticas sociais, interagindo com outros atores sociais e com a produção de sua cultura (Schneider, 2007). A nova cultura, na qual as crianças estão inseridas, os espaços que as crianças ocupam atualmente, produzem infâncias globalizadas em contato direto com o mundo. Esses espaços reconfiguram a infância contemporânea, visto que as crianças têm acesso a outras formas de imaginar, sentir, pensar e construir sua realidade infantil. Os ciberinfantes têm hoje, a possibilidade de conversar em tempo real, seja por e-mail, sejam comunicadores instantâneos (MSN) e sites de relacionamento. Ao fazer o uso destas possibilidades virtuais interativas, as crianças encontram novas formas de se sociabilizar e se produzir como sujeitos infantis hoje (Dornelles, 2007).

Prensky (2001) caracteriza essa geração de nativos digitais como as crianças que nasceram em contato com a sociedade em rede e não conseguem imaginar o mundo antes da rede mundial de computadores (Web), que os conecta com todo o mundo. Para o autor, a criança é um agente social que interpreta seu mundo e sua vida de forma particular, através de múltiplas interações simbólicas estabelecidas pelas crianças entre si e com o outro.

Portanto, neste estudo, entende-se a criança como aquela que faz parte da sociedade, estabelecendo relações sociais, interagindo com seus pares e demais membros de seu contexto sócio-cultural, com um modo de pensar próprio. Dessa forma, a infância é entendida não só como um tempo cronológico, mas como um tempo de sentido, de acontecimento e de experiência particularizadas em relação a estes tempos e contextos. Neste estudo, denomina-se ciberinfância essa infância atual que faz parte das pedagogias culturais que concorrem para engendrar as crianças numa variedade de espaços sociais, incluindo, mas não se limitando ao espaço escolar (Dornelles, 2005).

Veen e Vrakking (2009) chamam esta geração de crianças de homo zappiens, ou seja, crianças que demandam novas abordagens e métodos de ensino para que se consiga manter a atenção e a motivação na escola. Esses autores (IBID, 2009) ouviram relatos de professores que relatavam a mudança dos alunos que chegavam às escolas públicas de Estocolmo, na Suécia, no final da década de 1990. Comentavam que, repentinamente, as crianças que chegavam à escola demonstravam um comportamento bastante diferente, mais direto, ativo, impaciente e, de certa forma, indisciplinado. Parecia que algo diferente havia acontecido durante as férias. Para eles as crianças, com auxílio dos recursos computacionais, entraram em contato com um mundo sem fronteiras e com respostas 
instantâneas. Afirmam que ao utilizar as ferramentas de comunicação e colaboração da web, elas processam uma quantidade enorme de informações, por meio de uma grande variedade de tecnologias. Portanto, trazer o trabalho com as tecnologias digitais para a sala de aula a tentativa de problematizar o que acontece com esta frente ao ciberespaço.

\section{PROFESSORES IMIGRANTES DIGITAIS COMO CO-AUTORES DA EDUCAÇÃO}

Os professores deste início do século XXI são cunhados como imigrantes digitais e se apropriam dos recursos digitais ao longo de sua vida. Utilizam os recursos da rede ainda de forma limitada, mas buscam modos de reaprender sobre as tecnologias. Assim, os cenários de socialização vividos pelos nativos digitais se tornam muito diferentes do que foi vivido por esses professores (Sancho e Hernández, 2006). Neste contexto, o maior desafio dos educadores é problematizar as relações entre a infância e o mundo atual globalizado cujos ciberinfantes têm acesso desde que nascem (Dornelles, 2005).

Esse paradigma aponta para a necessidade de se promover mudanças urgentes nas formas de se pensar a educação por parte dos próprios autores da educação, professores, gestores e alunos. Vendo-os como sujeitos que sabem aprender, desaprender e reaprender constantemente. Entretanto o que tem ocorrido são professores que são instigados a uma ação docente que muitas vezes descarta suas capacidades de pensar, refletir, inventar e entrar no jogo da aprendizagem (Collares, 2008). Ao tratar os professores como co-autores do processo educativo propõe-se uma educação para além de conteúdos estabelecidos previamente, ou seja, busca-se a compreensão das ações dos alunos, constituindo-lhes novos significados. Assim, é possível destituir-se do planejamento fechado, abrindo novas possibilidades de trabalho, de acordo com a demanda dos alunos. Nessas situações uma das maiores ferramentas a ser utilizada pelo professor é reordenar o seu ouvir, sua curiosidade, reunir os parceiros, dizer de sua observação e entendimento, ouvir a opinião dos envolvidos em relação ao que expôs inclusive das crianças. Isso significa sair do sistema fechado e seguro do trabalho previamente planejado, no qual as ações são previsíveis, e assumir a constituição de um sistema aberto e complexo, que se constrói a partir da real atividade dos sujeitos (Collares, 2008), abandonar a tranquilidade de suas verdades para construir múltiplas verdades com seus alunos. Os ciberinfantes demandam essa abertura e essa possibilidade de novas construções que o professor pode oferecer se abrir para o dinâmico e fluido de sua ação docente na sala de aula. Essa pode ser propulsora de ações criativas que levem à construção de conhecimento pelos alunos.

Assim, para promover mudanças, transformações na educação, com o uso das tecnologias, Sancho e Hernández (2006) ensinam que é preciso uma mudança na cultura pedagógica e tecnológica das escolas. Oferecer alternativas para superar as limitações que dificultam a mudança e a melhoria dos ambientes educativos é uma necessidade cada vez mais evidente. Assim, o desenvolvimento de objetos de aprendizagem para a formação de professores pode representar um agente de mudança e modificação das práticas pedagógicas da escola.

\section{OBJETOS DE APRENDIZAGEM PARA A FORMAÇÃO DE PROFESSORES}


Entende-se necessário uma aliança entre professores, interesses dos ciberinfantes e a qualificação do uso que fazem das ferramentas tecnológicas. Precisam também confrontar suas práticas com novas formas de se trabalhar, valorizando a não-linearidade de conteúdo e o trabalho a partir da perspectiva do aprender entre aluno e pprofessores.

Entende-se que Objeto de Aprendizagem (AO) é qualquer recurso digital como: textos, animação, vídeos, imagens, aplicações, páginas Web, que se destinam a apoiar o alunos e professores no processo de aprendizagem. São recursos digitais modulares, usados para apoiar a aprendizagem presencial e à distância (Behar, 2009). Visando a formação de professores, portanto, os objetos de aprendizagem (OA) apresentam-se como uma possibilidade de disponibilizar conteúdos de forma mais dinâmica e atraente na Internet. Nesse sentido, tem-se realizado estudos para o desenvolvimento desses materiais, enfocando temáticas contemporâneas relativas à ciberinfância, práticas pedagógicas, utilizando recursos tecnológicos digitais, cultura e aprendizagem (Behar et al. 2009b) ${ }^{2}$, contribuindo para a atualização e reflexão dos professores em serviço, viabilizando a aplicação das tecnologias digitais na realidade escolar.

Nessa perspectiva, são pesquisados e desenvolvidos Objetos de Aprendizagem para atualização de professores de Educação Infantil e Anos Iniciais. Para a estruturação dos OAs, segue-se os padrões do RIVED ${ }^{3}$, um site referente a um programa do governo que incentiva a produção de Objetos de Aprendizagem e os publica na web. Para sua disponibilização e visualização na Internet, esses são cadastrados no repositório Coletânea de Entidades de Suporte ao uso de Tecnologia na Aprendizagem (CESTA), onde os professores por meio de busca, a eles acessam. À medida que um objeto de aprendizagem é construído, requer-se a sua validação. Assim, ao final do desenvolvimento dos OAs é oferecido um Curso de Extensão para professores, contribuindo para a sua formação e para uma aproximação desses sujeitos com os recursos da Internet.

\section{OBJETO DE APRENDIZAGEM PRÁTICAS CRIATIVAS NA WEB 2.0}

O tema criatividade vem sendo discutido constantemente na educação, possuindo diversas definições e promovendo grandes debates, como, por exemplo, "o que é ser criativo?”. Apresentando definições a partir de estudiosos em educação, optou-se por seguir Piaget (2001), sobre a criatividade. Para o autor, o conhecimento é construído através de estruturas, que não são pré-formadas. Dessa maneira, a cada nova estrutura construída pelo sujeito, há um processo de criatividade. Para a formação desse sujeito criativo, são dadas três condições, que consistem na necessidade de se trabalhar sozinho, na leitura de informações de diversas áreas e na existência de um adversário intelectual. Pode-se dizer, assim, que quando o indivíduo interage, constrói, re-inventa, ele também está sendo criativo.

Atualmente, um dos meios com os quais há grandes possibilidades de se poder criar, é em rede, visto que a diversidade de jogos informações e desafios, disponíveis na web 2.0 contribui para construção das aprendizagens. Além disso, os softwares sociais, presentes na web 2.0, podem proporcionar aos sujeitos situações práticas em que se possa

\footnotetext{
${ }^{2}$ Estudos sobre diferentes objetos de aprendizagem, voltados para formação de professores. Estes objetos estão disponíveis em http://www.nuted.ufrgs.br/objetos

${ }^{3}$ Rede Ibero-americana de Informática Educativa, disponível em: http://rived.mec.gov.br
} 
analisar e refletir sobre as ações e seus resultados, compreendendo-os na medida em que sua mente cria instrumentos para interpretá-los.

Assim, foi desenvolvido o objeto de aprendizagem "Práticas Criativas na Web

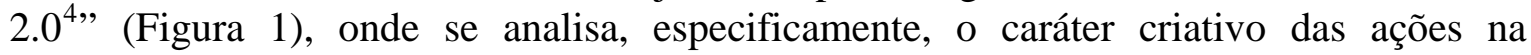
construção do conhecimento de si e do mundo, nas relações da sociedade em rede. Assim, a criatividade e o processo que envolve professores e alunos em AVAs aponta para a relevância desse trabalho quanto às discussões sobre a formação de professores, como sujeitos que criam. Neste trabalho, acredita-se que nos ambientes virtuais as relações hierárquicas são relativizadas, pois muitas vezes os alunos “dominam”, mais do que os professores, tais ferramentas da Internet. Contudo, para que os professores também possam dominar essas ferramentas e trabalhar com criatividade necessitam embasamento teórico e ação-reflexiva, conhecendo e pensando sobre os recursos informáticos disponíveis na Internet.

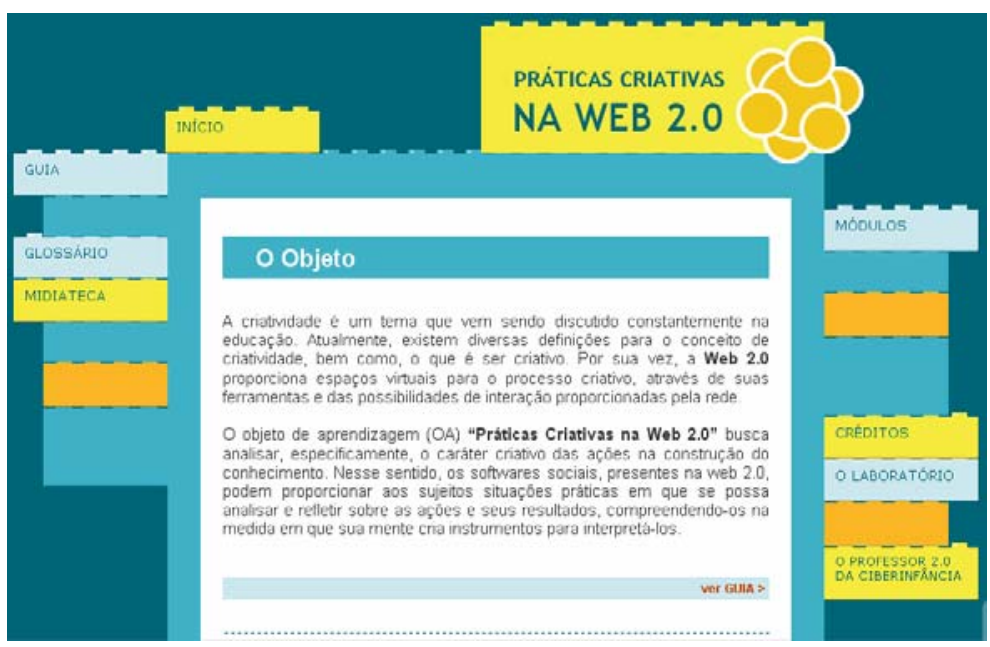

Figura 1: Tela de entrada do Objeto Práticas Criativas na Web 2.0

Os tópicos apresentados nesse objeto são divididos em 4 módulos: (1) definições diversas de criatividade a partir de correntes teóricas como, Construtivismo, Behaviorismo, Gestalt, entre outros; (2) ciberinfante criativo relacionando as dificuldades dos professores que não estão preparados para fazer uso das tecnologias que são de conhecimento das crianças; (3) os espaços criativos na web 2.0 e seus diferentes espaços bem como esses satisfazem as expectativas e anseios da ciberinfância e (4) planejando de forma criativa, onde se discute como tornar um ambiente virtual de aprendizagem agradável e atrativo, de forma que os ciberinfantes possam envolver-se nas atividades propostas.

Para esse objeto, a metáfora utilizada propõe uma interface em forma de blocos de brinquedo tipo Lego, explorando a criatividade e aprendizagem das crianças, suas possibilidades e limitações no uso desta ferramenta. Sua aplicação também serve para corresponder às características da Web 2.0, que visa uma maior interação com o usuário, a exemplo da tecnologia de Drag'n Drop utilizada, onde é possível ajustar o layout da página ao seu próprio desejo.

O mesmo apresenta também um guia para seus usuários, desafios, glossário e uma midiateca com links de diversas mídias sobre as temáticas desenvolvidas.

\footnotetext{
${ }^{4}$ Disponível em: http://www.nuted.edu.ufrgs.br/objetos_de_aprendizagem/2009/criativas/index.html
} 


\section{OBJETO DE APRENDIZAGEM PROFESSOR 2.0 DA CIBERINFÂNCIA}

O Objeto de Aprendizagem "Professor 2.0 da Ciberinfância" 5 " (Figura 2) discute a infância que convive com as tecnologias digitais, denominada de ciberinfância (Dornelles, 2005) e sua relação/integração com as práticas pedagógicas no espaço escolar. Essa infância tem como característica, o conhecimento do uso do computador. Desde muito cedo as crianças navegam, se comunicam e interagem através da Internet com grande espontaneidade. Além disso, utiliza-se o conceito de Prensky (2001) nativos digitais, ou da geração, que vive no mundo da Web 2.0, significando uma segunda geração da Internet. Estes visam a participação, comunicação, interação e produção destes usuários (os nativos digitais). Atualmente, observa-se que algumas escolas não consideram o uso dos recursos que as crianças já estão possuem, gostam e se interessam e o efeito disso são as dificuldades em inserir-se no mundo dos ciberinfantes. Dessa maneira, no ambiente escolar, as diferenças entre imigrantes (professores) e nativos (ciberinfantes) tornam-se mais evidentes. As tecnologias digitais estão presentes no processo ensino-aprendizagem destes nativos, imbricadas em suas ações. Estes parecem viver e pensar com essa tecnologia, enquanto muitos de seus professores "imigrantes digitais" continuam a utilizar apenas o giz branco e um quadro negro quando muitas escolas lhes oferecem todo um suporte tecnológico.

Cabe destacar que este OA foi desenvolvido a partir de dados levantados junto a diferentes grupos de professores em ações de Extensão do decorrer do ano de 2008- 2009. Os educadores envolvidos na pesquisa tiveram oportunidade de formular questões, trazer dúvidas, experiências, erros e acertos ao desenvolverem seus projetos utilizando a tecnologia digital na escola.

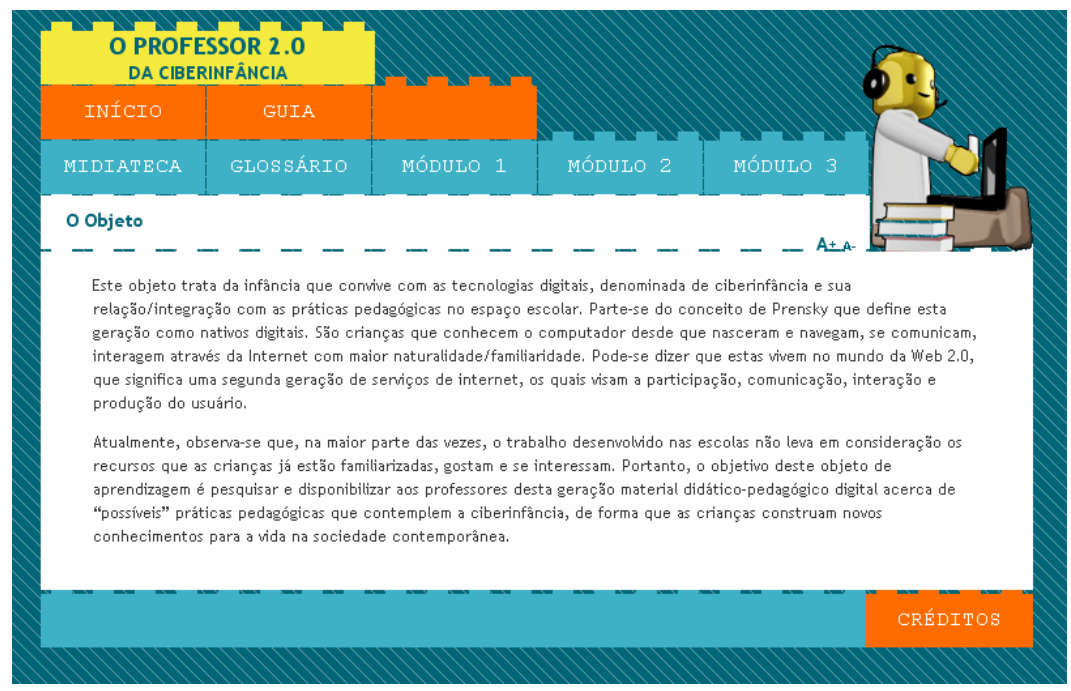

Figura 2: Tela de entrada Objeto Professor 2.0 da Ciberinfância

Tais demandas deram subsídios aos tópicos apresentados nesse objeto que se fundamenta em esclarecer e relatar algumas temáticas e experiências destes professores.

\footnotetext{
${ }^{5}$ Disponível em: http://www.nuted.edu.ufrgs.br/objetos_de_aprendizagem/2009/professor20/index.html
} 
Esses módulos são compostos de: (1) O professor como imigrante digital; (2) Mundos Virtuais; (3) Práticas pedagógicas do professor 2.0, que serão descritos a seguir.

O módulo “O professor como imigrante digital” objetiva estudar a ciberinfância e os conhecimentos produzidos por esta na Web, de algum modo isto contempla as crianças ciber que compõem atualmente, muitas escolas. Conhecidas como nativos digitais (Prensky, 2001), tais crianças possuem o domínio das tecnologias, já que as utilizam desde muito pequenas. Além disso, são abordadas as características dos adultos que nasceram antes da difusão da tecnologia digital, que são conhecidos como imigrantes digitais, pois aprenderam e conheceram os computadores e outros aparelhos eletrônicos ao longo de suas vidas.

No segundo módulo, "Mundos virtuais", são apresentadas as virtualidades disponibilizadas pela Web e que podem ser utilizados no processo de ensinoaprendizagem. Assim, apresenta-se a definição de "mundo virtual” que caracteriza-se por compor-se de uma tecnologia de interface avançada entre um usuário e um sistema computacional. Esta tecnologia tem por finalidade recriar a realidade de cada indivíduo através da interação que ocorre em tempo real, com o uso de técnicas e de equipamentos computacionais que buscam a ampliação do sentimento de presença "viva” de cada usuário. Desta forma, os mundos virtuais podem apresentar-nos reações muito próximas do universo real que conhecemos, já que a interação ocorre através da utilização de avatares, onde cada indivíduo é representado no mundo virtual por um personagem que varia desde um sofisticado modelo 3D até uma simples imagem.

Por fim, o terceiro módulo, "Práticas pedagógicas do professor 2.0" analisa a prática pedagógica com o encontro das ações intencionais de professores e ações dos alunos no contexto escolar. Além disso, são apresentadas alternativas para o uso de Tecnologias de Informação e Comunicação (TICs) em sala de aula.

Além dos módulos, esse Objeto também apresenta um Guia, que contém as possibilidades de uso de seus materiais; Glossário, com definição dos termos utilizados nos textos, mapas e apresentação de slides; Desafios, que procuram explorar a diversidade de aspectos relacionados à temática abordadas no Objeto, podendo relacioná-los à prática pedagógica do professor; Midiateca, com textos, vídeos e apresentações sobre temas do Objeto, bem como os textos complementares para resolução dos desafios e para maiores informações dos mesmos. Contudo, para o acesso aos links da Midiateca, faz-se necessária a conexão com a Internet.

Nesse Objeto, a interface também é apresentada em forma blocos de Lego semelhante ao Objeto Práticas Criativas na Web 2.0, tendo como personagem principal, um professor que está “domina” diferentes tecnologias, utilizando diferentes fontes de informação.

\section{A FORMAÇÃO DE PROFESSORES COMO EXPERIÊNCIA DE VALIDAÇÃO, AVALIAÇÃO E DIVULGAÇÃO DE OBJETOS DE APRENDIZAGEM}

Para analisar como esses OAs podem contribuir na formação de professores e na mudança efetiva de sua prática pedagógica, o foco desta pesquisa está na análise das ações dos principais personagens do processo educativo: professores e alunos em um ambiente de trocas e aprendizagem. Assim, a estratégia desencadeadora desta pesquisa é uma ação de Extensão com professores interessados em trabalhar na perspectiva da criatividade com a Web 2.0. Dessa forma, pretende-se analisar como os mesmos tramarão os princípios 
teóricos da criatividade com a sua ação docente, além do processo de criatividade da turma no ambiente escolar. Para execução desta ação de Extensão, a qual iniciou em maio de 2010, a mesma foi divulgada em escolas, através da página da UFRGS e em jornais de grande circulação. O objetivo era obter um público diversificado para as análises posteriores.

Com mais de 50 professores inscritos na ação de Extensão, o público se caracteriza por professores de Educação Infantil, Séries Iniciais e Finais do Ensino Fundamental, bem como estudantes de licenciatura em diferentes áreas do conhecimento. Para a pesquisa com os alunos, serão selecionados de 3 a 6 professores com regência de classe; para a segunda etapa, no trabalho junto as turmas de alunos, estas serão selecionadas de acordo com o projeto proposto pelo professor e com o auxilio dos pesquisadores do curso. Pretende-se trabalhar com professores e alunos três momentos: 1 ) com crianças de $1^{\circ}$ ao $3^{\circ}$ anos; 2) alunos do $4^{\circ}$ ao $5^{\circ}$ ano; 3) turmas entre o $6^{\circ}$ e o $9^{\circ}$ ano do Ensino Fundamental.

Os projetos propostos utilizarão os pressupostos de Romeike (2007) para que o planejamento busque a criatividade dos alunos, utilizando as ferramentas informáticas, apresentadas e discutidas no decorrer do curso. Para o autor, estes critérios beneficiam o trabalho docente, à medida que o planejamento organiza o mesmo, mas não o engessa. Onde o planejamento se trama com os alunos, com suas ações, imprevistos no ato de planejar. Porém, ao realizar esta ação, o professor pode antecipá-la e depois de realizá-las refletir sobre elas. Os quaro critérios principais para o planejamento criativo, nesse sentido, são (IBID, s/p): 1)Conteúdo: é importante levar em conta a relevância do tema para os alunos, bem como, o tipo de problema a ser resolvido ou o que se espera como produto final; 2) Atividades: devem trazer elementos novos para a temática, ou seja, novidades desafiadoras sobre determinados assuntos. O autor também sugere que se trabalhe a partir da perspectiva de construção de métodos para resolução de problemas, de forma que os alunos possam articular seus conhecimentos em busca de um elemento novo. Para realizar este trabalho é importante que o professor tenha claro qual o seu conceito de conhecimento e de aprendizagem e, a partir disso, como pretende aplicá-lo e qual será o ponto de partida dos alunos; 3)Foco_nos alunos: para uma prática criativa é preciso envolver os alunos na atividade, sendo fundamental que a criança identifique-se com as atividades. Isso implica que o conteúdo tenha significado para o aluno e que os objetivos estejam evidenciados. Cabe destacar que cada aluno é sujeito com ideias próprias, visões e preferências. Portanto, é preciso abrir espaço para a originalidade do aluno; 4)Ambiente de aprendizagem: a ação pedagógica do professor, ou seja, seus experimentos a seem propostos e um amplo tempo a ser disponibilizado. $\mathrm{O}$ incentivo à diversidade de idéias, onde o professor é um orientador da aprendizagem e seu centro.

Como suporte teórico para o curso estão sendo utilizados os OAs apresentados nesse artigo. Serão realizados ao todo 90horas de encontros presenciais oito meses. Na parte teórica do curso, propõe-se a utilização de um Ambiente Virtual de Aprendizagem para a postagem das produções e dos objetos de aprendizagem. Far-se-á uso de relatos e apresentações de projetos que estão sendo desenvolvidos pelos professores nas turmas. Dessa forma, pretende-se analisar ao mesmo tempo a ação docente e sua representação sobre sua prática.

\section{CONSIDERAÇÕES FINAIS}


A pesquisa encontra-se em sua etapa de validação para levantamento de dados acerca do impacto dos OAs na formação dos professores, com a perspectiva de mudanças e reflexão sobre sua prática pedagógica. Busca-se com esses Objetos, proporcionar debates acerca das implicações que estão sendo apresentadas com as constantes mudanças constantes dessas novas infâncias. Dessa maneira, o Objeto disponibiliza aos professores desta geração, um material didático-pedagógico digital que barca as práticas pedagógicas que contemplem essa ciberinfância.

Além dessa ação de Extensão, esses Objetos serão utilizados em disciplinas da Graduação e Pós-graduação da Faculdade de Educação da Universidade Federal do Rio Grande do Sul, com sua validação e avaliação ao longo do presente ano. Dessa forma pretende-se desenvolver Objetos cada vez mais próximos das necessidades dos usuáriosprofessores.

\section{REFERÊNCIAS}

AMANTE, Lúcia e MORGADO, Lína, (2001). Metodologia de Concepção e Desenvolvimento de Aplicações Educativas: o caso dos materiais hipermedia. In: Revista Discursos: língua, cultura e sociedade, Portugal, v. 3, n. especial, p. 27-44.

AMARAL, Caroline B. Desafio da ciberinfância: a composição de práticas pedagógicas com artefatos tecnológicos digitais para ciberifância. Dissertação de Mestrado, Universidade Federal do Rio Grande do Sul, 2009

BEHAR, Patricia. Modelos pedagógicos em educação a distância. Porto Alegre: Artmed, 2009.

CASTRO E SOUZA, Ana P. F de. A criatividade no AVA Planeta 2.0: os nativos digitais na escola do ciberespaço. Proposta de Dissertação de Mestrado, Universidade Federal do Rio Grande do Sul, 2010.

COLL, César; MONEREO, Charles. Psicologia da educação virtual: Aprender e ensinar as tecnologias da informação e da comunicação. - Porto Alegre: ARTMED, 2010.

COLLARES, Darli. O jogo no cotidiano da escola: uma forma de ser e estar na vida. In: Projeto - Revista de Educação: o jogo na sala de aula. Porto Alegre: Projeto, 2008.

DORNELLES, Leni Vieira. Infâncias que nos Escapam: da criança na rua à criança cyber. Petrópolis, RJ: Vozes, 2005.

HERNÁNDEZ, Fernando; SANCHO, Juana M. Tecnologias para transformar a educação. - Porto Alegre: Artmed, 2006.

LEVIN, Esteban. Rumo a uma infância virtual? A imagem corporal sem corpo. - Petrópolis, RJ: Vozes, 2007.

PIAGET, Jean. Criatividade. In: VASCONCELLOS, M. S. (org.) Criatividade: psicologia, educação e conhecimento do novo. São Paulo: Moderna, 2001.

PRENSKY, Marc. Digital natives, Digital immigrants. On the Horizon. United Kingdom, MCB University Press, v. 9, nº 5. 2001.

SCHNEIDER, Daisy. PLANETA ROODA: desenvolvendo arquiteturas pedagógicas para Educação Infantil e Anos Iniciais do Ensino Fundamental. Dissertação de Mestrado.- Porto Alegre: UFRGS, 2007.

São Paulo: Madras, 2008.

VEEN, Wim; VRAKKING, Ben. Homo Zappiens: educando na era digital. Vinicius Figueira (Trad.) Porto Alegre: Artmed, 2009. 